\title{
An overview of satellite remote sensing for landuse planning with special emphasis in Malaysia
}

\begin{abstract}
The use of land is perhaps the most basic of all environmental issue. Sound landuse is fundamental both to preserve stable ecosystems and control pollution. Agriculture, mining, industrial, urbanization and forestry development programmes, are given priorities in developing countries. This involves changes in the landuse pattern which is a very significant increase in production, extension of irrigation facilities and massive increase in other inputs. To implement these programmes successfully and to ensure effective conservation and rational utilization of natural resources, comprehensive and systematic information on the existing landuse pattern and various resources as well as their potential productivity are urgently required. The satellite remote sensing data provides' economic development planners, with excellent starting point for mapping and monitoring resources as well as environmental changes. For developing countries with incomplete and/or outdated resources and environmental maps remote sensing data can provide both base maps and thematic maps which are useful for national and regional planning. This paper emphasises the role of satellite remote sensing and its interface with other remotely sensed data to produce vital information necessary for landuse planning in Malaysia. It intends to review specific examples of the applications of this technology to landuse planning so that it can properly be harnessed in the future as an operational tool for landuse planning and development programmes in Malaysia.
\end{abstract}

Keyword: Satellite; Remote sensing; Landuse; Planning 